\title{
Biofuel application and design of small waterfall flame
}

\author{
W L Chen ${ }^{a^{*}}$, F L Chao, K T Lin \\ ${ }^{a}$ Department of Industrial Design, Chaoyang University of Technology, Taichung, 436, Taiwan
}

\begin{abstract}
For any product design to comply with regulations, knowledge of both combustion physics and safety is essential. In this study, a metallic and meshed wick structure was designed using fluid principles to reflect the increased demand of biofuel to replace alcohol. Biofuel has a flash point of up to $104^{\circ} \mathrm{C}$. The maximum temperature at the tip of a cord can reach $900^{\circ} \mathrm{C}$, and the fuel burns completely. Complete combustion ensures that a tabletop lamp is safe for use. Including a glass plate in the design facilitates the chimney effect. A firepot displays 3D waterfall flash. A CAE tool was used to predict the flow pattern. Quadrilateral elements were used to model the device. Overheating of a flame lamp can be prevented by including a guiding channel and ventilation holes. Applying fluid mechanics principles, designers can include safety features from the early stage.
\end{abstract}

Keywords: Biofuel, product design, safety, waterfall flame

\section{Introduction}

Firepots are marketed as decorative heating and lighting sources. In general, they comprise an outer housing and a small cup filled with an alcohol-based fuel. The required amount of fuel is related to the duration of the burning flame and must be refilled when the fuel is exhausted. Under inappropriate conditions, the refilling process may be dangerous.

\subsection{Alcohol fuel refilled accident}

The United States (US) Consumer Product Safety Commission (CPSC) has identified fire and burn hazards associated with a class of products frequently referred to as "firepots." A crucial feature of such products is the open-ended design of their fuel reservoirs (Fig. 1). In Europe, the US, and Australia, laws have been promulgated to prohibit the use of alcohol fuel in this type of fireplace.

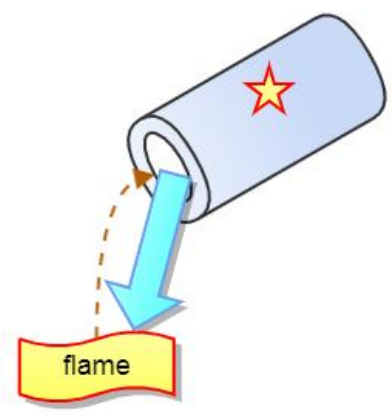

Fig. 1 Open-ended design of fuel reservoir

\footnotetext{
* Manuscript received 10 04, 2018; revised 12 25, 2018.

Fang-Lin Chao. Tel.: 886-928603905; E-mail address: flin@cyut.edu.tw.

doi: 10.12720 /sgce.8.3.299-306
} 
The open-ended design carries the risk of burn hazards when adding fuel (Fig. 1). An alternative configuration may improve safety by physcially seperating the fuel reservoir and the flame [1]. Fuel viscosity is an aggravating factor in firepot accidents. For low-viscosity fuels, the size of the spill is a function of fuel volume and its viscosity: [2]

$$
\mathrm{D}=0.373(\sigma \mathrm{Vt} / \mu)^{1 / 4}
$$

where $\mathrm{D}$ is the pool diameter $(\mathrm{m})$

$\sigma$ is the surface tension of the fuel $(\mathrm{N} / \mathrm{m})$

$\mathrm{V}$ is the volume of fuel spilled $(\mathrm{L})$

$\mathrm{t}$ is the time after the spill (s)

$\mu$ is the viscosity of the fuel

Viscosity is a function of temperature, and the fuel in a burning firepot is anticipated to have lower viscosity than fuel in a nonburning firepot. Increasing the incline to $20^{\circ}$ may be beneficial. The vapor pressure of alcohol at room temperature results in the formation of a flammable fuel-air mixture [3]. Moreover, a low-viscosity fuel is advantageous because in case of a spill, the mass of fuel to which a potential victim is exposed may be lower than that in the case of a fuel gel.

\subsection{Fuel demand}

Safety can be partially improved by controlling the flow of alcohol, for example, by using a micromotor. An additional alcohol controller is developed for the alcohol fuel device. When the device is dumped, the micromotor controller is activated, and the fuel is automatically turned off to maintain safety.

Flammable fire, explosion, and ignition properties are discussed in [4]. The types of alternative fuels available are described, as are the ignition and explosion hazards of commonly used fuels. Hydrogen may be prone to spontaneous ignition under high pressure.

International regulations relating to flame devices have been recently promulgated. Product design must be adjusted to comply with such regulations. The use of fuels is governed by chemical, combustion, and physical properties. The demand for a new fuel has spurred the development of biofuel as a replacement for alcohol. Such safe fuels are widely used now.

\subsection{Safety regulations}

In recent years, several safety regulations have been established. Some of these regulations are related to the safety of fuels, the toxins produced after burning, and their environmental impact. A product must be certified before it is sold in the market. The relevant regulations are listed as follows:

UL Standard 525 Standard for Flame Arresters [5] mandates vent deflagration flame arresters and inline detonation flame arresters and applies to arresters used on vents of storage tanks for petroleum oil and gasoline. These flame arresters are used to prevent flame propagation into storage tanks. Flame arresters can be unidirectional or bidirectional and are designed to prevent detonation and deflagration. The test procedures include endurance burn test, flashback tests, and deflagration tests.

ISO 16852:2016, Flame Arresters-Performance Requirements, Test Methods, and Limits for Use states requirements for flame arresters that prevent flame transmission in the presence of explosive gasair mixtures. It details basic construction and test methods to ensure safety and to determine the safe limits of use.

European Standard EN 1127-1:2007 [6] details the risk assessment of equipment designed for use in potentially explosive atmospheres. The sources of ignition under normal operations are maintenance activities, stopping and disconnection, operational problems, and incorrect use. Safety can be realized by ensuring the following in the stated order:

1. Ensure that ignition sources cannot arise;

2. Ensure that ignition sources cannot become effective;

3. Prevent explosive atmospheres from reaching the ignition source.

EN 14015 is a standard for the design and manufacture of vertical, cylindrical, above-ground, and 
welded steel tanks with flat bottoms. The European design code for fuel tanks includes the design and manufacturing of site-built, above-ground, and welded steel tanks for the storage of liquids at ambient temperature.

The study of regulations in various potential markets is crucial for marketing decorative flames and fireplaces. Australian AGA certification [7] states that benzene levels should decrease with increasing ethanol concentration and stipulates that tailpipe emissions should have less toxins. Acetaldehyde and formaldehyde emissions will increase. Extraordinary measures are required to control evaporative emissions from products using alcoholic fuels.

The US and Australian government agencies are evaluating further restrictions on the use of stationary alcohol fuels. Alcohol is subject to restrictions based on market regulations in various countries, and the complete specifications for alcohol use in Europe and the US have been released. The alcohol product market is shrinking as customers are demanding a safer fuel system.

\section{Biofuel}

Flame devices with high flash point fuels can replace hazardous alcohol fuels. The original alcohol suppliers have withdrawn from the market, and alcohol fuel suppliers are actively seeking safe alternative fuels. Government policies are promoting the setting up of supply chain mechanisms for biodiesel production from various sources, including nonedible oilseeds, used cooking oil, and short gestation crops, which reduce greenhouse gas emissions.

\subsection{Biounifuel features}

Researchers are seeking renewable substitutes for petroleum-based fuels. Alcohol-based biofuels are those in which conventional fuels are partly mixed with biofuels [8]. The biofuels are comprised of two components: (A) dimethoxymethane with one of the less preferred compounds, such as ethyl nitrate, which is capable of improving the combustion speed and (B) propylene glycol monoalkyl ether, which is used to replace propoxyalcohol and butoxy alcohol. The boiling point ranges from $39^{\circ} \mathrm{C}$ to $190^{\circ} \mathrm{C}$ depending on composition.

Ethanol $\left(\mathrm{C}_{2} \mathrm{H}_{5} \mathrm{OH}\right)$ is an alcohol and an oxygenated organic carbon compound widely used in chemical industries. Ethanol is most frequently used as a motor fuel primarily as a biofuel additive for gasoline. Cellulosic ethanol is ethanol produced from cellulose and not from the seeds or fruits of plants. It is a biofuel produced from grass, wood, algae, and other plants. Ethanol fuels are expected to be crucial in the future.

Biounifuel has a flash point of up to $104^{\circ} \mathrm{C}$ (Fig. 2), which does not result in accidental ignition due to changes in environmental conditions. Therefore, it can be stored and transported safely. The fuel burns inside a stainless-steel core under certain conditions; when spills occur, the fuel cannot burn as these conditions no longer exist.

When liquid fuel is adsorbed in the stainless-steel core, the high flash point fuel is gradually transferred upward along the center and is heated to reach the combustion condition. If the fuel is sprayed directly onto the burning wick, the fuel is not adequately warmed. Thus, the flame does not grow, thus complying with safety regulations. An SGS combustion test showed that the sample produces low-density carbon monoxide.

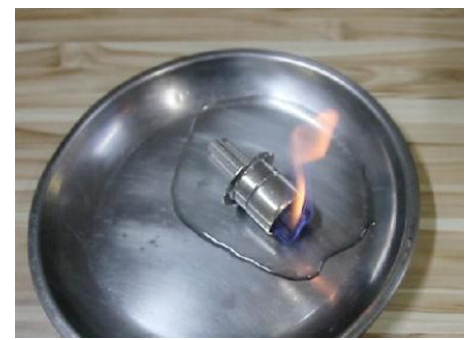

Fig. 2. Ignition point of biofuel is $104^{\circ} \mathrm{C}$, which ensures low environmental impact and high safety. The burning time is longer than that of ethanol fuel. When accidentally knocked over, the flame goes out quickly [9]. 


\subsection{Extant safe fuel}

Brand-B Clean Burn Fuel is 85\% plant-based [10] (Fig. 3) and produces less soot and smoke than do petroleum-based fuels [11]. It is less harmful to the environment than are conventional fuels. This fuel is refined from crude oil. Numerous chemicals can be derived from crude oil, such as gasoline, diesel fuel, and torch fuel. Naphthas or eucalyptus products are liquid and widely used as solvents and fuel.

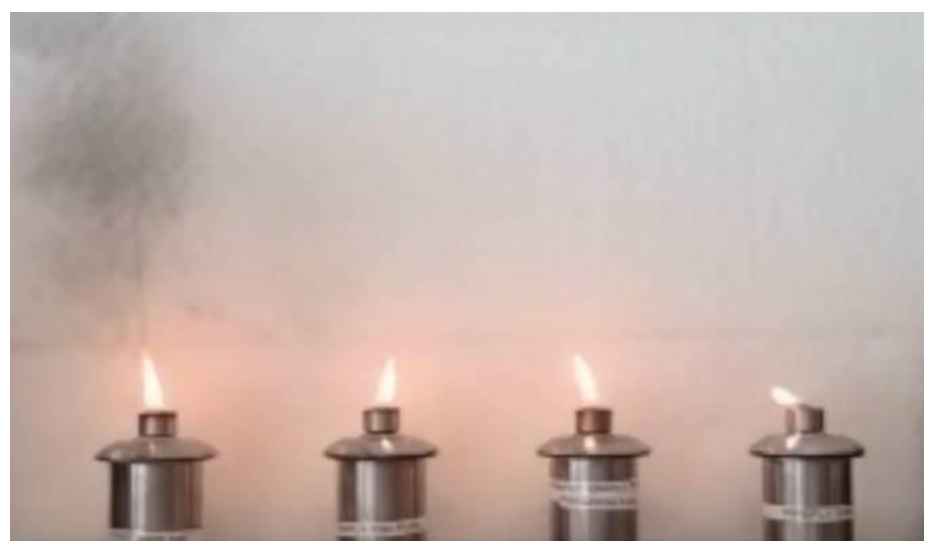

Fig. 3. Burn test (second to the left) [11]

Brand-B fuel, for oily fuels and the use of fiberglass wicks, the required materials are different. The fuel is partially environment friendly. The specification reveals special stimulation to the eyes and skin harm. Environment friendly fuels require complete combustion. Therefore, the fuel is suitable for outdoor usage, but it has certain restrictions on its use.

\subsection{Fuel testing}

Both types of biofuels were evaluated. The combustion products were carbon dioxide and water vapor. The visibility of the flame was higher than that of alcohol. The biofuels burned completely at a fast rate and with no black smoke.

The combustion process produces only $22 \mathrm{ppm}$ of trace carbon monoxide, considerably less than the human hazard standard. When burning in a closed space, oxygen content gradually decreases; when the oxygen content is less than $18 \%$, the flame is automatically extinguished. Thus, carbon monoxide poisoning or suicide incidents can be avoided.

When burning, due to the reduction in the oxygen content, the metal wick cannot maintain a high temperature; thus, gasification of fuels with a high flash point is impossible, thereby causing automatic flameout and combustion interruption and ensuring safety. The fuel with high flash point cannot be easily used for automatic electronic ignition. The related technology must be improved to reduce power consumption.

According to CSA standards, indoor fireplaces should automatically shut down when the oxygen level is less than $18 \%$. Under this oxygen level, clean combustion is difficult and can cause CO concentration. The fuel stops burning before a high concentration of $\mathrm{CO}$ is generated. The stainless wick minimizes the risk from producing poisonous carbon monoxide during burning in small, sealed chambers.

Because the wick material is not involved in combustion, no chemical change is observed in the stainless-steel core, which increases durability. If the stainless-steel core is placed in a normal $\mathrm{pH}$ environment, the service life can be as high as 2000 hours because of its low corrosion rate. 


\section{Flame Innovative Design}

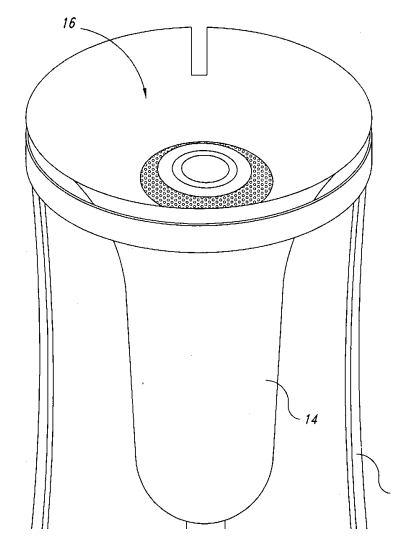

Fig. 4 Decorative torch [12]

Biofuel can be used with torches, table torches, and firepieces. A decorative torch generates a luminous flame as an aesthetically pleasing light source (Fig. 4). A filter received in a passage of a fuel tube minimizes acoustical noise generated by a pressurized fuel source. The fuel is citronella oil.

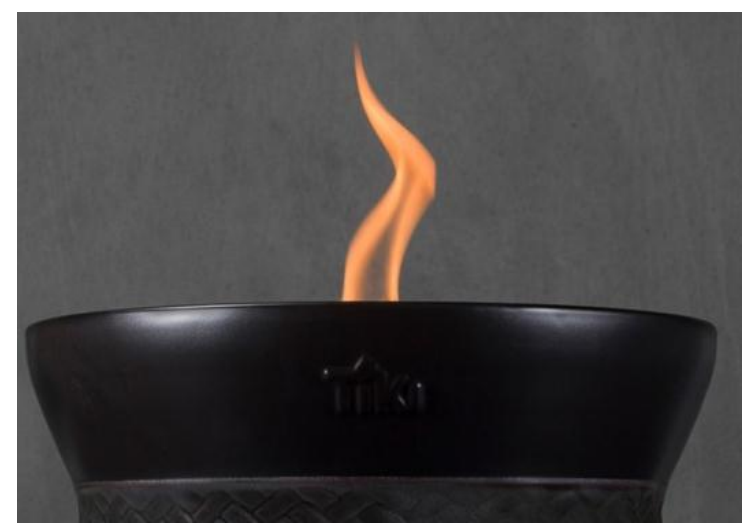

Fig. 5. Table torches using brand-B fuel [10]

The design uses a round wick and generates a curvature flame (Fig. 5). The tabletop fire piece emits less smoke and soot. The absorbent wick reduces the risk of fuel spillage. The primary body constructed is constructed using ceramic.

\subsection{Stainless steel wick}

Chen used a moisture-retaining substance [13] with an alternative fuel and burns for an extended period. The stainless steel wick (Fig. 6) ensured complete combustion and the safety of the lamp. By using the principles of fluid mechanics and guiding channel, the overheating of the flame lamp was prohibited.

A series of combustion products with the waterfall flame design have been designed. The tip temperature reaches $900^{\circ} \mathrm{C}$ when burning with the stainless steel wick. The flame size ranges from small to large for different sources, including candlesticks, table atmosphere lamps, and indoor fireplaces. In compliance with the law, the waterfall flame provided aesthetics, high efficiency, and safety. 


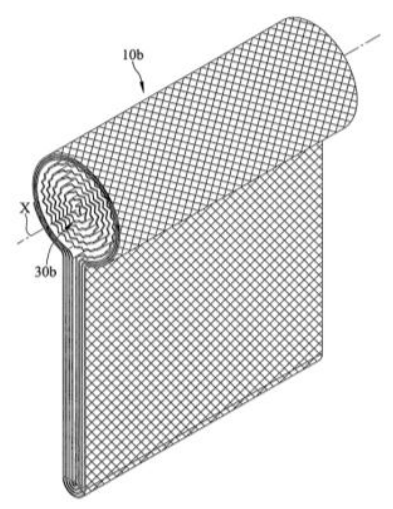

Fig. 6. Stainless-steel wick [13]

\subsection{CAE model of waterfall shape candlestick}

A flow field analysis was conducted to predict the pattern of the tabletop lamp. The 3D computer-aided design model was developed using the CATIA modeling platform. Mass and momentum were converted through the continuity of mass and Navier-Stokes equation, respectively [14].

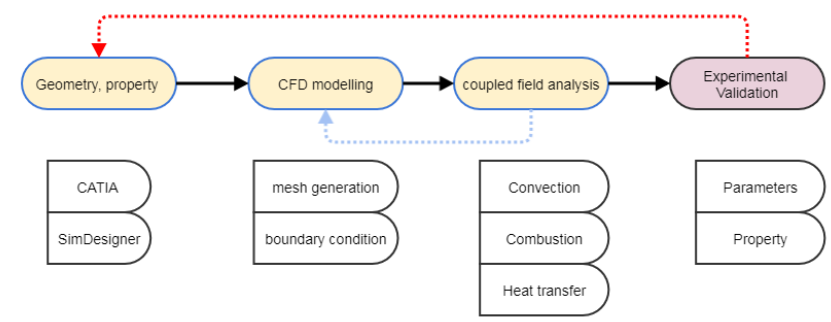

Fig. 7. Flowchart of CFD and combustion heat transfer computation

The numerical analysis tool ANSYS/Flotran applies the laws of mass continuity, momentum conservation, and energy conservation to calculate velocity, pressure, and temperature distribution. The flowchart (Fig. 7) presents the procedure of CFD analysis. Quadrilateral elements are used in modeling. The three types of boundaries conditions are wall, inlet, and outlet (Fig. 8).

The combustion phenomenon was modeled through coupled-field analysis. The interaction between disciplines was considered. The sequential method involves two sequential scans, and each scan belongs to a different field. The result of previous steps were applied as loads in the subsequent analysis.

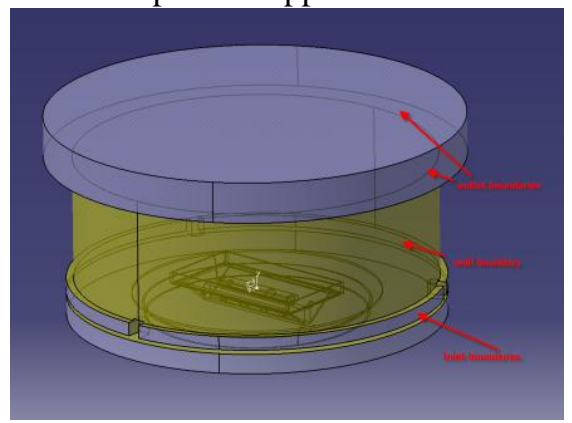

Fig. 8 Boundary conditions for setting a tabletop lamp using flow field analysis. 


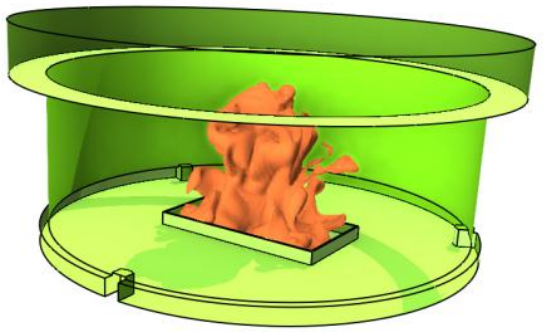

Fig. 9. Anticipated flame pattern

Fig. 9 shows the anticipated flame pattern. When combustion starts, the temperature increases and generates an ascending airflow in the glass tube, and asymmetrical turbulence is generated because of the flow of the intake air at the boundary of the rectangular block. The combustion air flow was elevated with some flutter. The simulation results indicate that the height of the flame is approximately $6.5 \mathrm{~cm}$.

\subsection{Experimental validation}

A prototype was developed using a stainless-steel base. The tempered glass is high-temperature resistant and is placed on two sides of the burner. The holes on the two sides of the burner are for air ventilation. The experiment successfully presented a waterfall flame pattern. The flame burnt on the wick (Fig. 10) and did not spread out when it was tipped over.

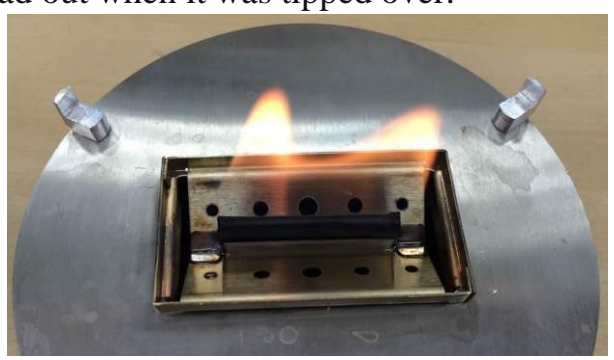

Fig. 10. Experimental validation of waterfall flame pattern

\section{Conclusion}

As the alternative fuel and stainless-steel wick ensured complete fuel combustion, the safety of the tabletop flame lamp was demonstrated in this study. By adjusting the shape of the air inlet, the runner and the vane, a decorative waterfall flame pattern was obtained. A guiding channel provided the cooling air intake and reduced the surface temperature. The glass plate promoted the chimney effect. The design process uses a numerical analysis tool to predict the flow pattern. By utilizing a guiding channel and ventilation holes, overheating of the flame lamp could be avoided when the flame overheats. By applying the principles of fluid mechanics, designers can provide safety features in the design stage.

\section{Acknowledgements}

The authors thank the students in the CAE Lab in Chaoyang University of Technology for their efforts and supplying the testing and measurement. This research is partially supported by the Pro-Iroda company with facilities and prototyping. 


\section{References}

[1] Marsh ND, Marsh ND. Evaluation of firepots and gel fuels. US Department of Commerce, National Institute of Standards and Technology, 2013.

[2] Barry J. Estimating rates of spreading and evaporation of volatile liquids. CEP Magazine, January 2005.

[3] Staff Briefing Package on Firepots and Gel Fuel. U.S. Consumer Product Safety Commission, December 7, 2011.

[4] Astbury GR. A review of the properties and hazards of some alternative fuels. Process Safety and Environmental Protection, 2008, 86(6): 397-414.

[5] Standard for Flame Arresters. UL Standard 525 (2011).

[6] Explosion Prevention and Protection. The European Standard EN 1127-1 (2007)

[7] Beer T, Grant T, Morgan G, Lapszewicz J, Anyon P, Edwards J, Williams D. Comparison of transport fuels report (EV45A/2/F3C). Australian Greenhouse Office, 2001.

[8] Araya M. Alcohol-based fuel and biofuel composition. U.S. Patent Application No. 11/463,963.

[9] Biounifuel. [Online]. Available: www.pro-iroda.com.tw/index.php/product/series/19

[10] Clean Burn. [Online]. Available: www.Brand-Bbrand.com/clean-burnt-tabletop-firepiece-ceramic-large.html [Online]. Available: https://www.fireflyfuel.com/tiki-torch-fuel-information/

[11] [Online]. Available: https://youtu.be/bPunnMAA0NE

[12] Konkle S. Decorative torch for use with pressurized fuel source. U.S. Patent Application No. 11/070,381.

[13] Chen, Wei-Long. Wick of Flame Device. U.S. Patent Application No. 14/302,485.

[14] Chu CY, \& Pan MC. Transient analysis and experimental validation of thermal-fluidic fields on TFT-LCD TV panels. In: Electronics Packaging Technology Conference, IEEE EPTC'06, 2006:346-352. 